\title{
FOPID Controlled Shunt Active Filter in IEEE Thirty Bus System with Improved Dynamic Time Response
}

\author{
S. Dhandayuthapani ${ }^{1}$, K. Anisha ${ }^{2}$ \\ ${ }^{1,2}$ Dept of EEE, SCSVMV University, Kanchipuram, Tamil Nadu, India
}

\begin{tabular}{l} 
Article Info \\
\hline Article history: \\
Received Feb 5, 2019 \\
Revised May 1, 2019 \\
Accepted Feb 18, 2020 \\
\hline Keywords: \\
PICSAF \\
FOPIDSAF \\
Thirty Bus System(TBS) \\
Open Loop Thirty Bus System \\
(OLTBS)
\end{tabular}

\begin{abstract}
This paper aims at improving the dynamic time response of a Wind Energy Conversion System (WECS) connected to IEEE Thirty Bus System (TBS) using Permanent Magnet Synchronous Generator (PMSG) in closed-loop controlled Active Power Filter with Fractional Order Proportional Integral Derivative (FOPID) controller. The objective of the FOPID controller is to reduce the steady state error and Total Harmonic Distortion (THD). The simulation results are presented to find the effectiveness of a shunt active filter using FOPID controller. An Open Loop Thirty Bus System (OLTBS) with a change in load is simulated. The simulation results with Proportional Integral (PI) and FOPID Controller based SAF are compared and the corresponding time-domain parameters are presented. The results indicate that FOPID Controller system has a better response than PI controlled system.
\end{abstract}

Copyright $($ C) 2019 Institute of Advanced Engineering and Science. All rights reserved.

\section{Corresponding Author:}

S.Dhandayuthapani, Research Scholar, Department of Electrical and Electronics Engineering,

SCSVMV University,

Kanchipuram, India.

Email: dhand_au@yahoo.com

\section{INTRODUCTION}

The usage for power electronic converters for various industries, commercial sectors and residential applications increases day to day due to their improvement in the technology. These static converters polluting the utility supply due to the harmonics and inter frequency components generated by them. Harmonics have adverse result on the facility system network and lead to excessive heating of neutral conductors, bus bars, lug connections, control and switchgear, which can have an effect on current interrupting capabilities, Circuit breaker nuisance tripping, malfunction of on-board breaker physical science, excessive arcing, improper fuse operation or blown fuse interruption (artificial heating or "skin effect"), Meter, protective relaying, control and other communication and measuring instrumentation devices (including ground fault detection and digital displays). A shunt active filter shown in Fig.1 below is an alternate solution to mitigate harmonics generated by the non-linear loads and also provides reactive support to the system, hence system power factor is improved.

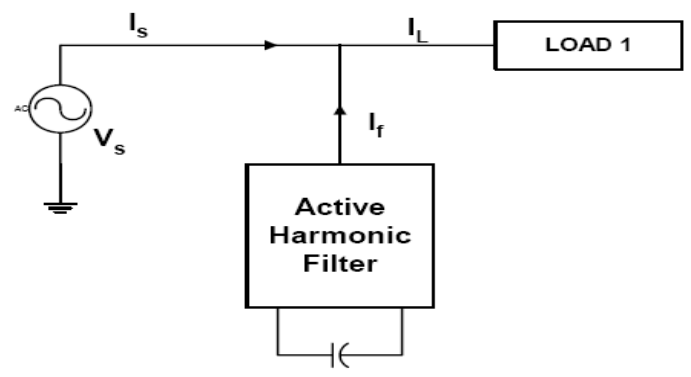

Figure 1. Shunt Active Power Filter block diagram 


\subsection{THEORY OF SHUNT ACTIVE POWER FILTER}

The concept of the Shunt Active Filter[1]-[2] is to produce harmonic compensating currents equal in magnitude but opposite in-phase to those harmonics that are present in the electric grid. The standard rules, just like the IEEE 519 limits the harmonics at the entranceway, enforce to limit the harmonic pollution. Passive filters [3] are cannot find the exact solution to the harmonics and poor power factor issue due to their sizes, resonance issues at apart from tuned frequencies, poor performance with variation in input frequency, etc. Fig. 2 illustrates the schematic representation of Active Filter.

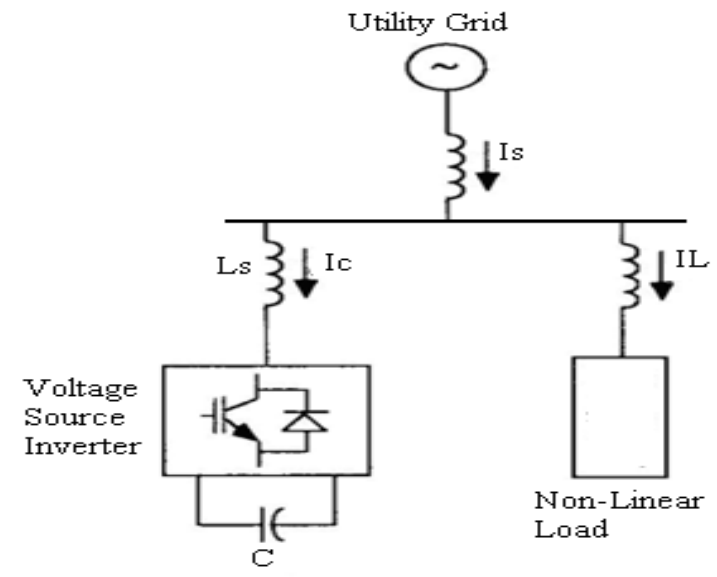

Figure 2. Schematic Representation of Active Filter

The shunt active filters are used to eliminate the unwanted harmonics and compensate fundamental reactive power consumed by nonlinear loads by injecting the compensation currents into the AC lines. Here, the shunt active filter operates as a current source so that it injects harmonic current into the AC system with the same amplitude as that of the load but with an opposite phase. This principle is applicable to a variety of loads. The APF has VSI and a series inductor.

\subsection{SHUNT ACTIVE FILTER WITH PI /FOPID CONTROLLER}

Fig. 3 shows the block diagram of the implemented PI/ FOPID control scheme of a shunt active filter. PI/FOPID controller is used to generate switching pulses with the help of the Pulse Width Modulated( PWM) controller. Active Power Filter has a solution to Power Quality (PQ) problems in the distribution network is given by Rudnick [4]. Proportional resonant controlled SAF is an active filter in IEEE TBS with an improved response is given by Anisha [5]. FOPID controlled Interleaved Boost Converter(ILBC) fed SAF is suggested by Ramkumar [6]. A fundamental harmonic components of a load is extracted using Artificial Neural Network and harmonic current is compensated by using discrete fuzzy logic is reported in [7]. Authors in [8] have proposed a 5/5 rule-based Fuzzy Logic Controller (FLC) in combination with indirect current control is applied to the SAF in a single-phase system to improve the power quality. A Hybrid filter is operated as a variable harmonic conductance and eliminates the harmonic distortion in industrial power systems is reported in [9]. Authors in [10] have proposed an enhanced closed-loop current control scheme without using phase-locked loops (PLL), when Distributed Generation (DG) unit is connected to a grid with frequency deviation. In [11], power quality improvement by using a combination of shunt hybrid power filter and thyristor controlled reactor is reported. Digital control of a shunt hybrid power filter has a different scheme of approach such as nonlinear control and optimal control to meet IEEE Std. 519 current harmonic constraints under non-ideal supply condition have been reported in [12] and [13]. In [14], cascaded multilevel inverter for active harmonic filtering in distribution network is reported.

In [15] and [16], resonance control of modular three-level shunt active power filter is proposed and optimization algorithm for selective compensation technique is reported. In [17], predictive harmonic control and its optimal digital implementation for the Modular Multilevel Converter (MMC)-based active power filter are reported. Shunt active power filter based on cascaded transformers coupled with three-phase bridge converters and the experimental design of the adaptive backstepping control technique for single-phase shunt active power filters have been reported in [18] and [19]. Authors in [20] have proposed a Fuzzy logic controller for Grid-connected wind energy conversion system. Optimization of power quality control by using the PI and Fuzzy controller is reported in [21]. 


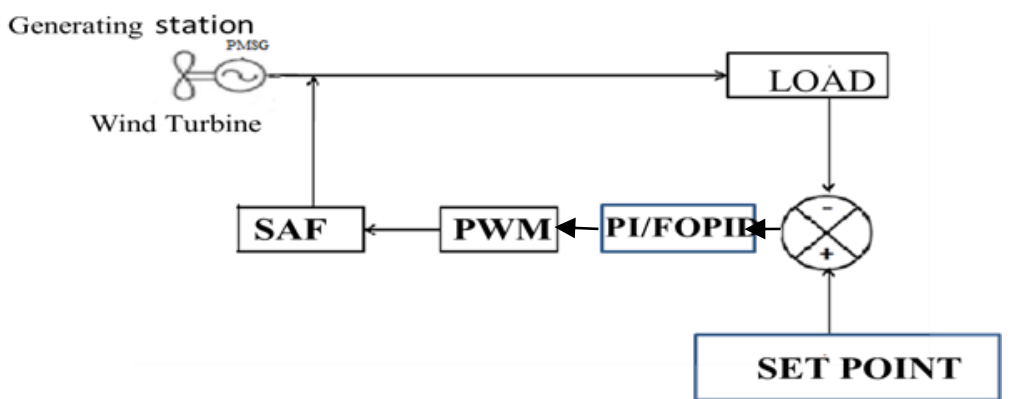

Figure 3. Block diagram of Shunt Active Filter with PI/FOPID controller

The output and inputs of the FOPID controller are related as follows

$$
F O P I D(s)=K_{p}+\frac{K_{i}}{s^{\lambda}}+K_{d} s^{\mu}------
$$

Here $\lambda$ and $\mu$ are fractions.

The Block diagram of Shunt Active Filter with PI and FOPID controller as shown above in Fig.3. The controller input is an error signal obtained from the reference voltage and the value r.m.s of the terminal voltage measured. Such error is processed by a PI/FOPID controller and the output is given to PWM signal generator. The output PWM signal generator chooses the task of the converter switches.

The literature [1]-[21] do not report the use of SAF for TBS. The comparison of responses of PI and FOPID controlled SAF in TBS is not reported. This work suggests SAF for TBS to improve thedynamic response and to reduce the THD.

\section{IEEE TBS WITH SAF}

The one-line diagram of TBS with SAF[5] is shown in Fig.4. This network has generators,wind buses and lines are modelled as per IEEE Standard TBS data. This transmission line network data for the buses are tabulated in the Appendix-I. In this network,a disturbance,i.e change in load is given in a $27^{\text {th }}$ bus and the corresponding dynamic time-domain parameters are measured at that bus.

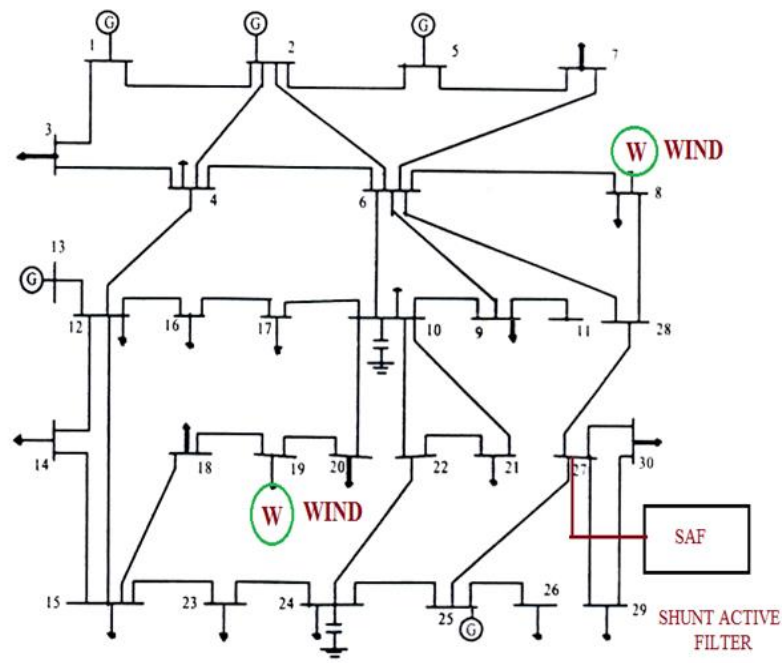

Figure 4. One line diagram of IEEE TBS with shunt active filter

\section{SIMULATION RESULTS}

Open Loop TBS with disturbance is shown in Fig.5. The Voltage at bus-27 of OLTBS is given in Fig.6. and its value is $2000 \mathrm{~V}$. RMS voltage at bus-27 of OLTBS is given in Fig.7 and its value is 1420 V. Current at bus27 of OLTBS is given in Fig.8. Real power at bus-27 of OLTBS is given in Fig.9 and its value is 0.019 MW. Reactive power at bus-27 of OLTBS is given in Fig.10 and its value is 0.022 MVAR. Current Total Harmonic Distortion (THD) at bus-27 of OLTBS is given in Fig.11.The increase in P and Q is due to an increase in voltage. 


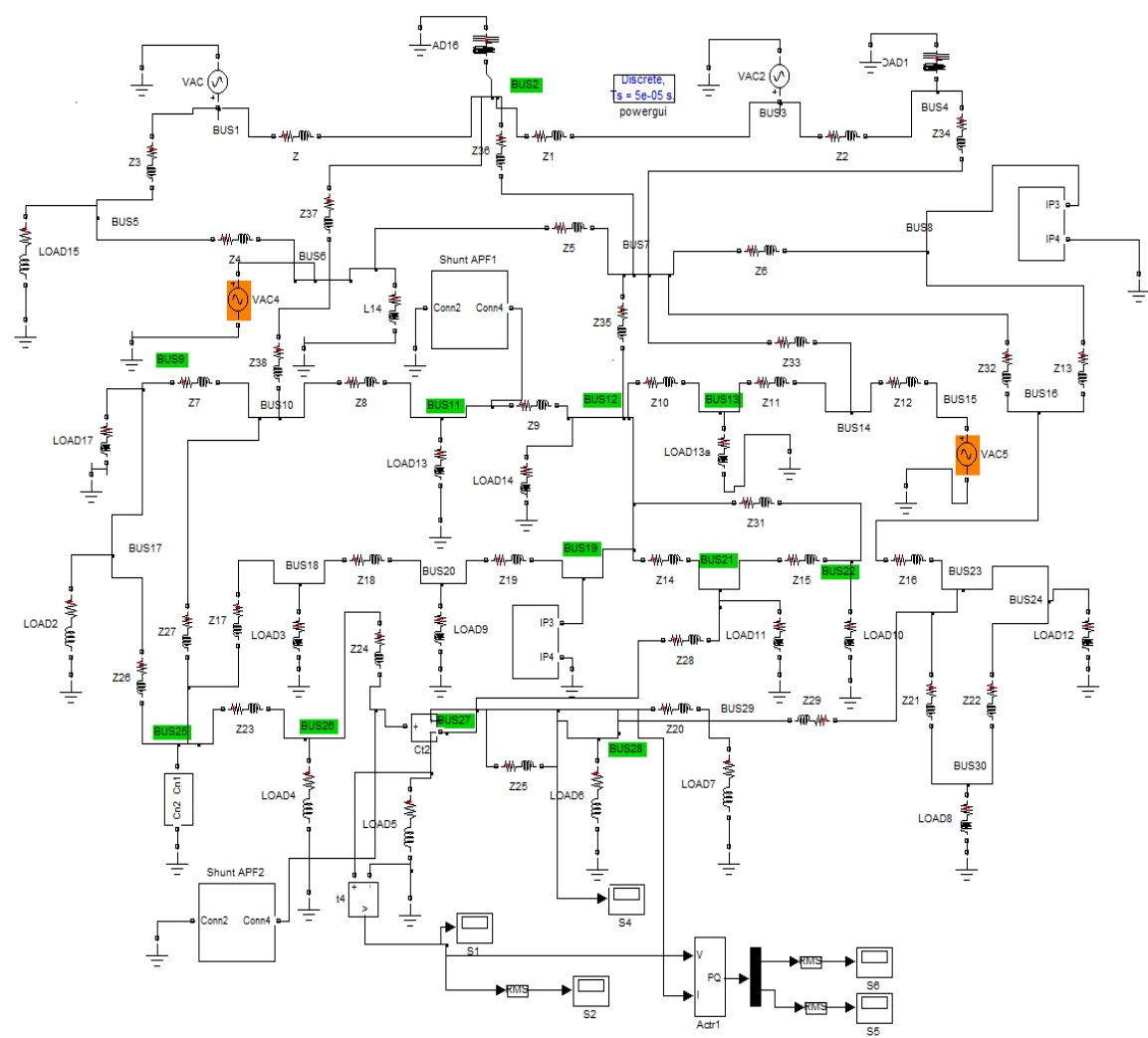

Figure 5. Open Loop TBS with disturbance

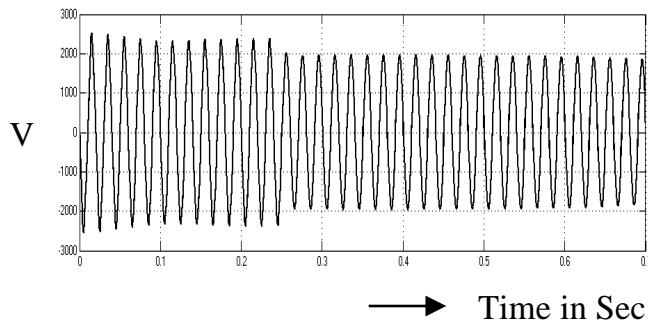

Figure 6. Voltage at bus-27 of OLTBS

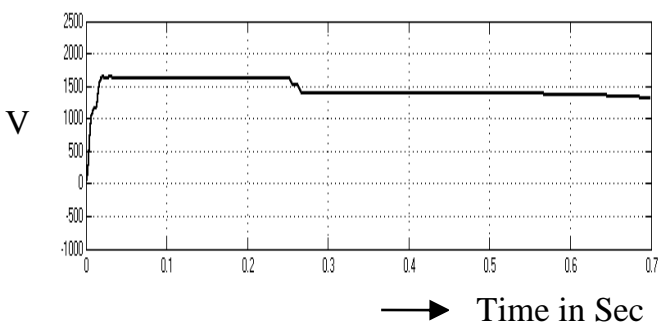

Figure 7. RMS voltage at bus-27of OLTBS

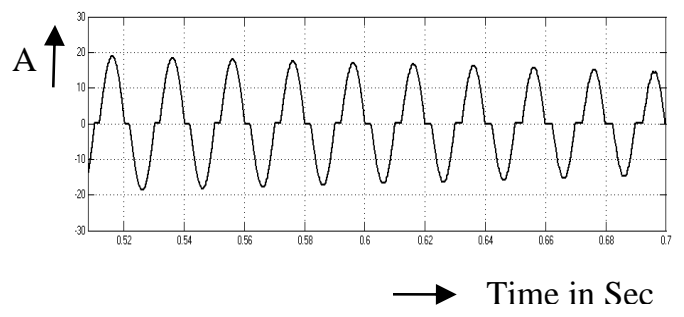

Figure 8. Current at bus-27 of OLTBS

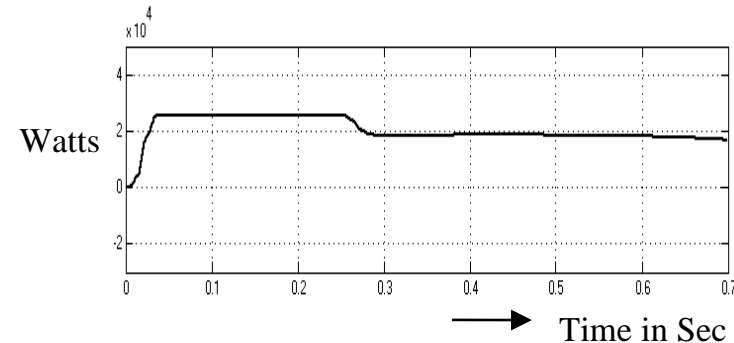

Figure 9. Real power at bus-27 of OLTBS

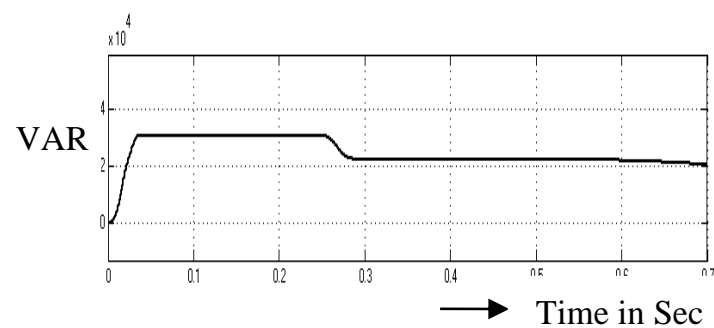

Figure 10. Reactive power at bus-27 of OLTBS

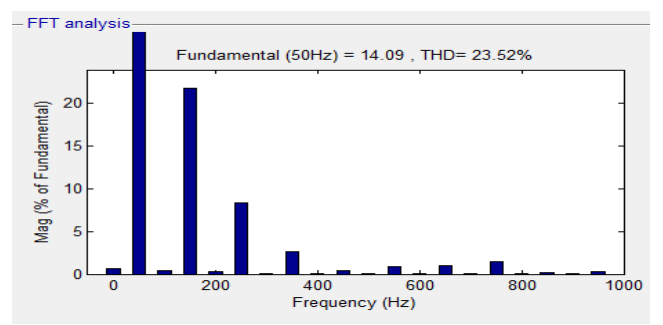

Figure 11. Current THD at bus-27 of OLTBS 
Closed loop TBS with PI controller is shown in Fig. 12.The Voltage at bus-27 of Proportional Integral Controlled Shunt Active Filter (PICSAF) is given in Fig. 13 and its value is 2000V. RMS voltage at bus-27 of PICSAF is given in Fig. 14 and its value is 1540 V. Current at bus-27 of PICSAF is given in Fig. 15. Real power at bus-27 of PICSAF is given in Fig. 16 and its value is $0.023 \mathrm{MW}$. Reactive power at bus-27 of PICSAF is given in Fig.17 and its value is 0.027 MVAR. Current THD at bus-27 of PICSAF is given in Fig.18. The increase in voltage is corrected by SAF. This is due to the reduction in pulsewidth.

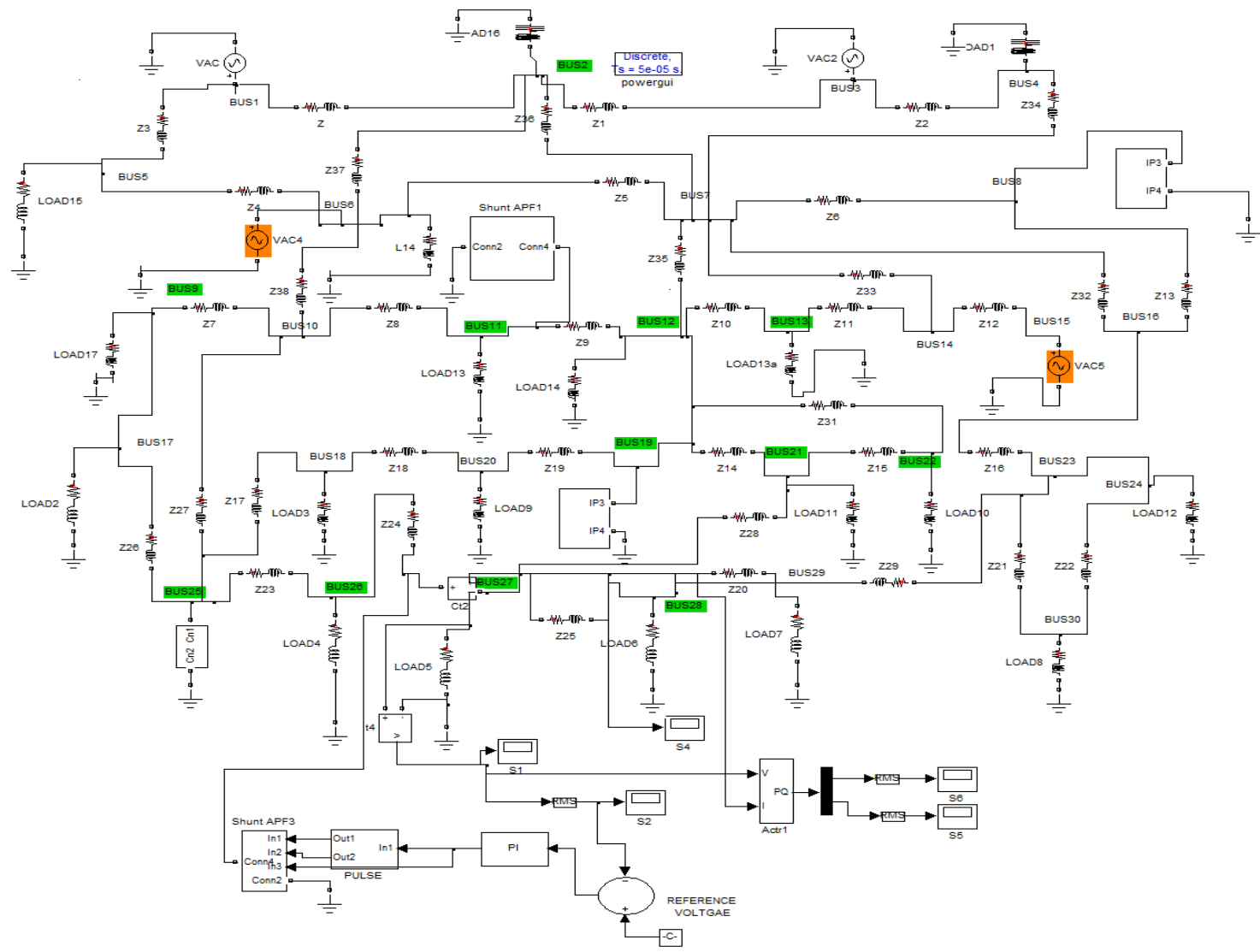

Figure 12. Closed loop TBS with PI controlled SAF

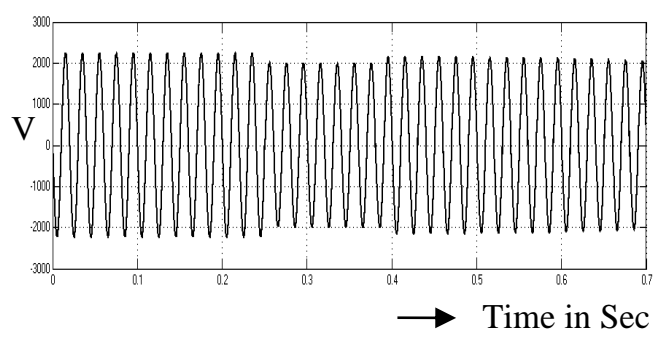

Figure 13. Voltage at bus-27 of PICSAF

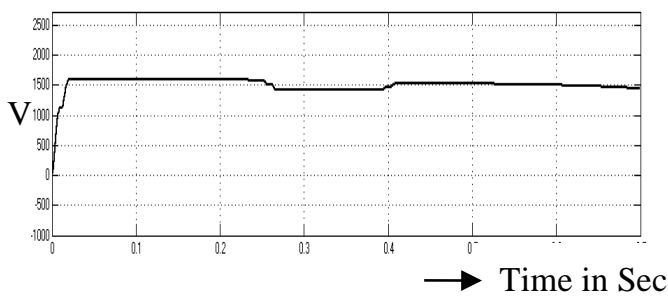

Figure 14. RMS voltage at bus-27 of PICSAF

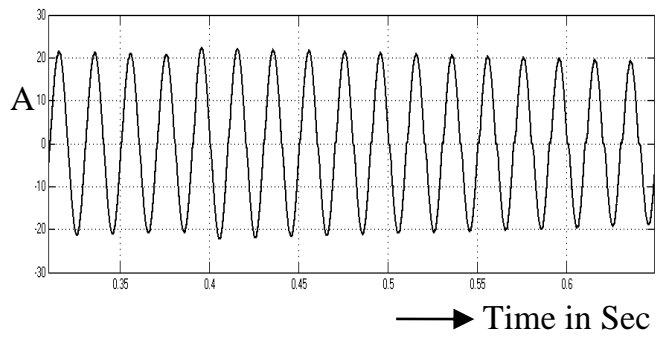

Figure 15. Current at bus-27 of PICSAF

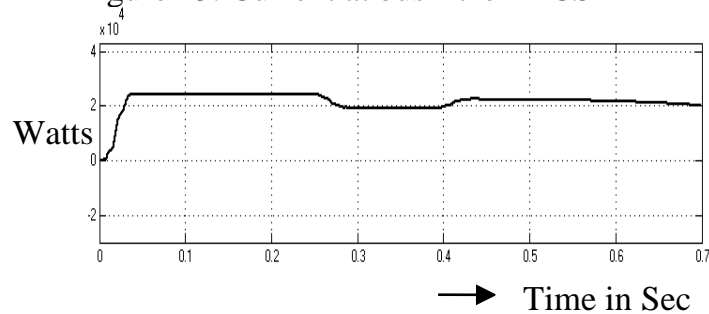

Figure 16. Real power at bus-27 of PICSAF

FOPID controlled Shunt Active Filter in IEEE Thirty Bus System with ...... (S.Dhandayuthapani et al) 


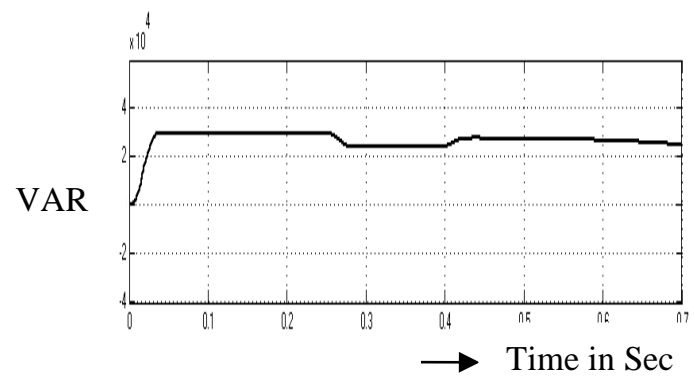

Figure 17. Reactive power at bus-27 of PICSAF

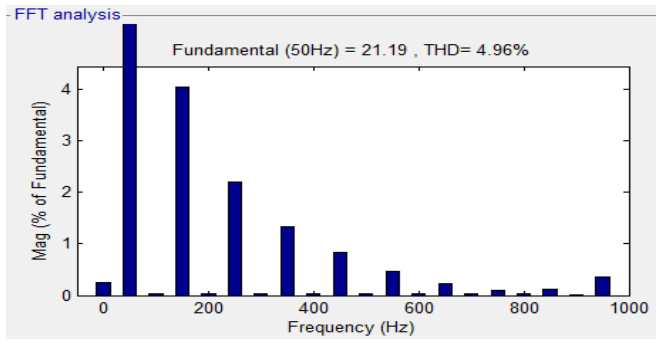

Figure 18. Current at bus-27 of PICSAF

Closed loop TBS with FOPID controller is shown in Fig. 19.The Voltage at bus-27 of Fractional Order Proportional Integral Derivative Controlled Shunt Active Filter (FOPIDCSAF) is given in Fig.20 and its value is 2000 V. RMS voltage at bus-27 of FOPIDCSAF is given in Fig. 21 and its value is $1545 \mathrm{~V}$. Current at bus-27 of FOPIDCSAF is given in Fig.22. Real power at bus-27 of FOPIDCSAF is given in Fig. 23 and its value is 0.024MW. Reactive power at bus-27 of FOPIDCSAF is given in Fig.24 and its value is 0.029MVAR. Current THD at bus-27 of FOPIDCSAF is given in Fig.25. It can be seen that the voltage brought back to the original value using FOPIDCSAF.

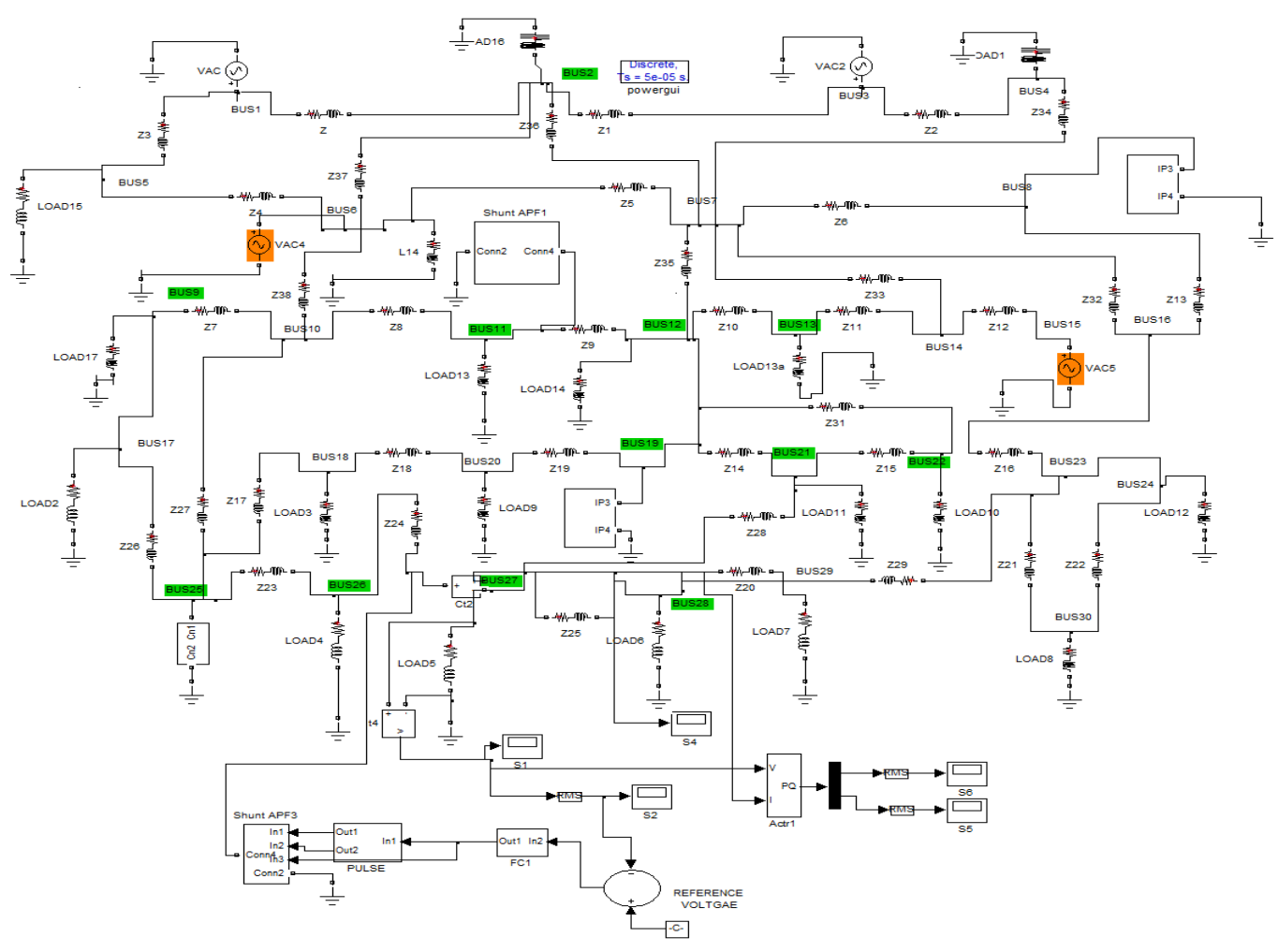

Figure 19. Closed loop TBS with FOPID controlled SAF

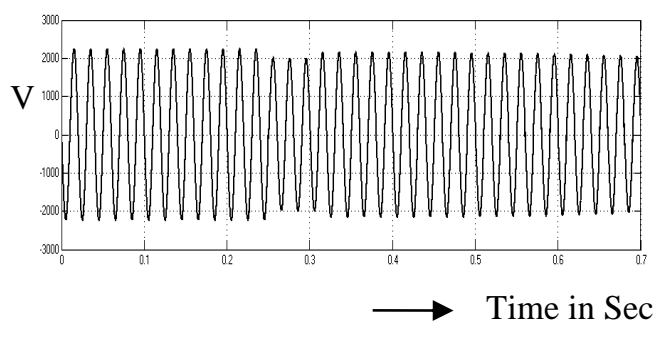

Figure 20. Voltage at bus-27 of FOPIDCSAF

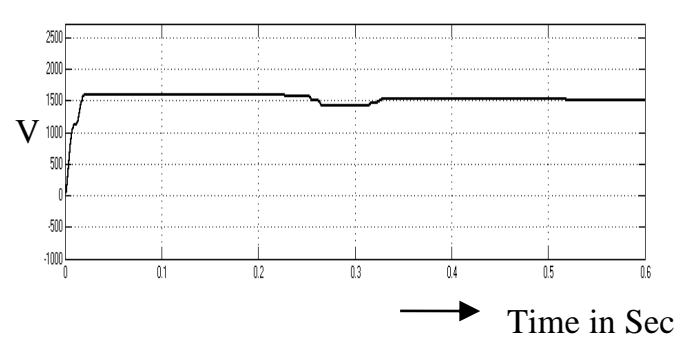

Figure 21. RMS voltage at bus-27 FOPIDCSAF 


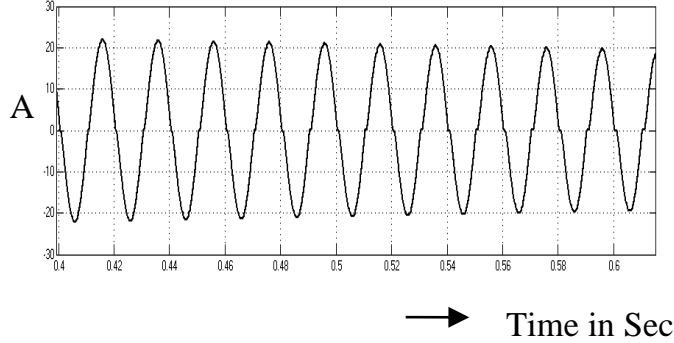

Figure 22. Current at bus-27 of FOPIDCSAF

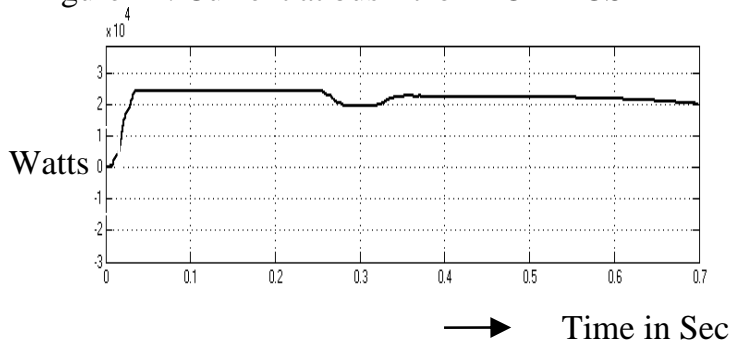

Figure 23. Real power at bus-27 of FOPIDCSAF

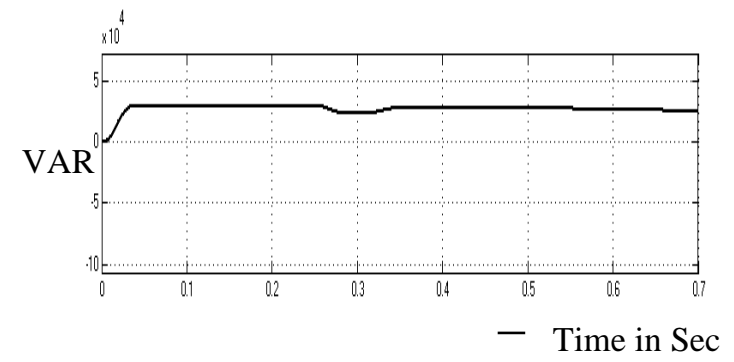

Figure 24. Reactive power at bus-27 of FOPIDCSAF

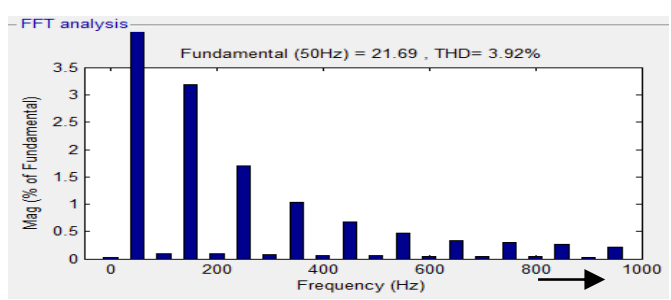

Figure 25. Current THD at bus-27 of FOPIDCSAZZ

Table 1. Comparison of time domain parameters for PICSAF and FOPIDCSAF

\begin{tabular}{ccccc}
\hline Controller & Rise time $(\mathrm{sec})$ & Peak time $(\mathrm{sec})$ & Settling time $(\mathrm{sec})$ & Steady state error $(\mathrm{V})$ \\
\hline PICSAF & 0.26 & 0.34 & 0.43 & 2.4 \\
FOPIDCSAF & 0.25 & 0.29 & 0.32 & 1.6 \\
\hline
\end{tabular}

A Comparison of time-domain parameters for PICSAF and FOPIDCSAF is shown in Table.1. By using the FOPID controller, the rise time is reduced from 0.26 to $0.25 \mathrm{sec}$; peak time is reduced from 0.34 to 0.29 sec; settling time is reduced from 0.43 to $0.32 \mathrm{sec}$; Steady-state error is reduced from 2.4 to $1.6 \mathrm{~V}$. Hence, for closedloop TBS, FOPIDCSAF is superior to PICSAF. The Dynamic response is also enhanced by using the FOPID controller.

Table 2. Comparison of Current THD for PICSAF and FOPIDCSAF

\begin{tabular}{cc}
\hline Controller & Current THD \\
\hline Open loop TBS & $23.52 \%$ \\
Closed loop PICSAF & $4.96 \%$ \\
Closed loop FOPIDSAF & $3.92 \%$ \\
\hline
\end{tabular}

A Comparison of current THD for PICSAF and FOPIDCSAF at bus 27 is given in Table-2. By using FOPIDSAF, THD is reduced to $3.92 \%$ compared to PICSAF. Hence, closed-loop TBS with FOPIDCSAF is superior to PICSAF.

\section{CONCLUSION}

Thirty bus systems in closed-loop are simulated and the results with PI and FOPID are presented. The steadystate error is reduced from $2.4 \mathrm{~V}$ to $1.6 \mathrm{~V}$. The settling time is reduced from 0.43 seconds to 0.32 seconds. Therefore FOPID based active filter may be a viable alternative to the existing controller. The reduction in settling time and steady-state error is very high in the case of FOPID controller system. The disadvantage of FOPIDCSAF is that it is not suitable for nonlinear systems.

The present work deals with the investigation of TBS. The improvement in power quality of TBS using Fuzzy controlled SAF will be done in the future. 
APPENDIX-I

LINE DATA AND LOAD DATA

\begin{tabular}{|c|c|c|c|c|c|c|}
\hline \multirow[t]{2}{*}{ BUS NO } & \multirow[t]{2}{*}{ VOLTAGE } & \multicolumn{2}{|c|}{ LOAD IMPEDANCE } & \multirow[t]{2}{*}{ BUS NO } & \multicolumn{2}{|c|}{ LINE IMPEDANCE } \\
\hline & & RESISTANCE & INDUCTANCE & & RESISTANCE & INDUCTANCE \\
\hline bus 1 & $6.3 \mathrm{kv}$ & - & - & bus $1-2$ & $1 \Omega$ & $30 \mathrm{mH}$ \\
\hline bus 2 & - & $10 \Omega$ & $100 \mathrm{mH}$ & bus $2-5$ & $3 \Omega$ & $38 \mathrm{mH}$ \\
\hline bus 3 & $6.3 \mathrm{kv}$ & - & - & bus $5-7$ & $6 \Omega$ & $40 \mathrm{mH}$ \\
\hline bus 4 & - & $85 \Omega$ & $120 \mathrm{mH}$ & bus 3-1 & $13 \Omega$ & $37 \mathrm{mH}$ \\
\hline bus 5 & - & $200 \Omega$ & $300 \mathrm{mH}$ & bus $4-2$ & $15 \Omega$ & $30 \mathrm{mH}$ \\
\hline bus 6 & $6.3 \mathrm{kv}$ & - & - & bus $6-2$ & $23 \Omega$ & $26 \mathrm{mH}$ \\
\hline bus 7 & - & $125 \Omega$ & $180 \mathrm{mH}$ & bus 6-7 & $45 \Omega$ & $56 \mathrm{mH}$ \\
\hline bus 8 & $6.3 \mathrm{kv}$ & - & - & bus $13-4$ & $54 \Omega$ & $63 \mathrm{mH}$ \\
\hline bus 9 & - & $135 \Omega$ & $167 \mathrm{mH}$ & bus $12-4$ & $43 \Omega$ & $100 \mathrm{mH}$ \\
\hline bus 10 & - & $58 \Omega$ & $127 \mathrm{mH}$ & bus $12-16$ & $36 \Omega$ & $113 \mathrm{mH}$ \\
\hline bus 11 & - & $100 \Omega$ & $100 \mathrm{mH}$ & bus $16-17$ & $24 \Omega$ & $55 \mathrm{mH}$ \\
\hline bus 12 & - & $10 \Omega$ & $100 \mathrm{mH}$ & bus $17-10$ & $36 \Omega$ & $85 \mathrm{mH}$ \\
\hline bus 13 & - & $48 \Omega$ & $100 \mathrm{mH}$ & bus $10-9$ & $78 \Omega$ & $125 \mathrm{mH}$ \\
\hline bus 14 & - & $67 \Omega$ & $97 \mathrm{mH}$ & bus $9-11$ & $85 \Omega$ & $79 \mathrm{mH}$ \\
\hline bus 15 & $6.3 \mathrm{kv}$ & - & - & bus $10-6$ & $96 \Omega$ & $150 \mathrm{mH}$ \\
\hline bus 16 & - & $33 \Omega$ & $65 \mathrm{mH}$ & bus 6-9 & $110 \Omega$ & $138 \mathrm{mH}$ \\
\hline bus 17 & - & $78 \Omega$ & $125 \mathrm{mH}$ & bus $6-28$ & $108 \Omega$ & $124 \mathrm{mH}$ \\
\hline bus 18 & - & $10 \Omega$ & $100 \mathrm{mH}$ & bus $15-14$ & $89 \Omega$ & $119 \mathrm{mH}$ \\
\hline bus 19 & $6.3 \mathrm{kv}$ & $120 \Omega$ & $150 \mathrm{mH}$ & bus $18-19$ & $76 \Omega$ & $106 \mathrm{mH}$ \\
\hline bus 20 & - & $120 \Omega$ & $168 \mathrm{mH}$ & bus $19-20$ & $79 \Omega$ & $98 \mathrm{mH}$ \\
\hline bus 21 & - & $125 \Omega$ & $130 \mathrm{mH}$ & bus $20-10$ & $86 \Omega$ & $110 \mathrm{mH}$ \\
\hline bus 22 & - & $25 \Omega$ & $90 \mathrm{mH}$ & bus $22-21$ & $55 \Omega$ & $103 \mathrm{mH}$ \\
\hline bus 23 & - & $110 \Omega$ & $138 \mathrm{mH}$ & bus $21-10$ & $40 \Omega$ & $75 \mathrm{mH}$ \\
\hline bus 24 & - & $10 \Omega$ & $100 \mathrm{mH}$ & bus $27-28$ & $55 \Omega$ & $69 \mathrm{mH}$ \\
\hline bus 25 & $6.3 \mathrm{kv}$ & $10 \Omega$ & $100 \mathrm{mH}$ & bus $28-30$ & $64 \Omega$ & $78 \mathrm{mH}$ \\
\hline bus 26 & - & $10 \Omega$ & $100 \mathrm{mH}$ & bus $27-30$ & $81 \Omega$ & $93 \mathrm{mH}$ \\
\hline bus 27 & - & $10 \Omega$ & $100 \mathrm{mH}$ & bus $15-18$ & $112 \Omega$ & $97 \mathrm{mH}$ \\
\hline bus 28 & - & $10 \Omega$ & $100 \mathrm{mH}$ & bus $15-23$ & $106 \Omega$ & $136 \mathrm{mH}$ \\
\hline bus 29 & - & $89 \Omega$ & $189 \mathrm{mH}$ & bus $23-24$ & $93 \Omega$ & $131 \mathrm{mH}$ \\
\hline bus 30 & - & $115 \Omega$ & $198 \mathrm{mH}$ & bus $24-22$ & $89 \Omega$ & $124 \mathrm{mH}$ \\
\hline & & & & bus $24-25$ & $40 \Omega$ & $75 \mathrm{mH}$ \\
\hline & & & & bus $25-26$ & $55 \Omega$ & $69 \mathrm{mH}$ \\
\hline & & & & bus $28-27$ & $64 \Omega$ & $78 \mathrm{mH}$ \\
\hline & & & & bus $27-29$ & $81 \Omega$ & $93 \mathrm{mH}$ \\
\hline & & & & bus $29-30$ & $112 \Omega$ & $97 \mathrm{mH}$ \\
\hline
\end{tabular}

\section{REFERENCES}

[1] Akagi H. "New trends in active filters for power conditioning". IEEE Trans Ind. Appl.,1996; 32(6): 131222

[2] A.Mansoor, W.M.Gardy, P. T. Staats, R. S. Thallam, M. T. Doyle, and M. J. Samotyj, "Predicting the net harmonic current produced by large numbers of distributed single phase computer loads." IEEE Trans Power Delivery, 2016;10:2001-2006.

[3] S.Dhandayuthapani,C.Sharmeela, "Proportional Resonant controlled shunt active filter in IEEE nine bus system with improved dynamic performance"International journal for Applied science and Engineering Tech (IJRASET),2018;6(1):1312-1320.

[4] H. Rudnick, Juan Dixon and Luis Moran, "Active power filters as a solution to power quality problems in distribution networks, "IEEE power \& energy magazine, 2003;32-40.

[5] S.Dhandayuthapani,K.Anisha, "Proportional Resonant Controlled Shunt Active Filter in IEEE Thirty Bus System with Improved Dynamic Time Response”.International Journal of Engg.and Tech.2018;7(4.19):334-339.

[6] Purigilla Venkata Ramkumar, Munagala Surya Kalavathi "Fractional Order PID Controlled Interleaved Boost converter Fed Shunt Active Filter System'”International journal of power electronics and drives system(IJPEDS) 2018; 9(1):126-138.

[7] L. Saribulut, A. Teke, M. Tumay, "Artificial neural network based discrete fuzzy logic controlled active power filter", IET Power Electronics, 2014;7(6):1536-1546.

[8] P.S. Puhan, P.K. Ray, G. Panda, "Development of Real Time Implementation of 5/5 rule based Fuzzy Logic Controller Shunt active Power Filterfor Power quality Improvement", IJEEPES,2016;17(6):607-617.

[9] T.-L. Lee, Y.-C. Wang, J.-C. Li, J. M. Guerrero, "Hybrid active filter with variable conductance for harmonic resonance suppression in industrial power systems", IEEE Trans. Ind. Electron., 2015;62(2):746-756.

[10] J. He, Y. W. Li, F. Blaabjerg, X. Wang, "Active harmonic filtering using current-controlled grid-connected DG units with closed-loop power control", IEEE Trans. Power Electron.,2014;29(2):642-653.

[11] Salem Rahmani, Abdelhamid Hamadi, Kamal Al-Haddad, Louis A. Dessaint, "A Combination of Shunt Hybrid 
Power Filter and Thyristor-Controlled Reactor for Power Quality", IEEE Transactions On Industrial Electronics,2014;61(5): 2152-2164.

[12] A. Hamadi, S. Rahmani, K. Al-Haddad, "Digital control of a shunt hybrid power filter adopting a nonlinear control approach", IEEE Trans. Ind. Inf.,2013;9(4):2092-2104.

[13] Hatem Zeineldin, Parag Kanjiya, Vinod Khadkikar, "Optimal control of Shunt Active Power Filter to meet IEEE Std. 519 Current Harmonic Constraints under Nonideal Supply Condition", IEEE Trans. On Power Electronics,2015;62(2):2015.

[14] Anup Kumar Panda, Sushree Sangita Patnaik, "Analysis of cascaded multilevel inverter for active harmonic filtering in distribution network", Electrical Power and Energy Systems,2015;66:216-226.

[15] L. Feng, Y. Wang, "Modeling and resonance control of modular three-level shunt active power filter", IEEE Trans. Ind. Electron.,2017;64(9):7478-7486.

[16] J. C. Alfonso-Gil, E. Perez, C. Arino, H. Beltran, "Optimization algorithm for selective compensation in a shunt active power filter", IEEE Trans. Ind. Electron., 2015;62(6):3351-3361.

[17] Z. Shu, M. Liu, L. Zhao, S. Song, Q. Zhou, X. He, "Predictive harmonic control and its optimal digital implementation for MMC-based active power filter", IEEE Trans. Ind. Electron.,2016;63(8):5244-5254.

[18] G. Carlos, C. B. Jacobina,E.Santos, "Shunt active power filter based on cascaded transformers coupled with threephase bridge converters", IEEE Trans. Ind. Appl.,2017;53(5):4673-4681.

[19] M. Salimi, J. Soltani, A. Zakipour, "Experimental design of the adaptive backstepping control technique for singlephase shunt active power filters", IET Power Electron.,2017;10(8):911-918.

[20] G.Muni Reddy,T.Gowri Manohar, "Fuzzy logic controller for Grid connected wind energy conversion system",Indonesian journal of Electrical Engineering and Informatics(IJEEI), 2018;6(1):37-44.

[21] Garim Sinha,Pankaj Kumar Goswami,Sudhir Kumar Sharma, "A comparative Strategy Using PI and Fuzzy Controller for Optimization of Power Quality Control", Indonesian journal of Electrical Engineering and Informatics(IJEEI), 2018;6(1):118-124.

\section{BIOGRAPHIES OF AUTHORS}

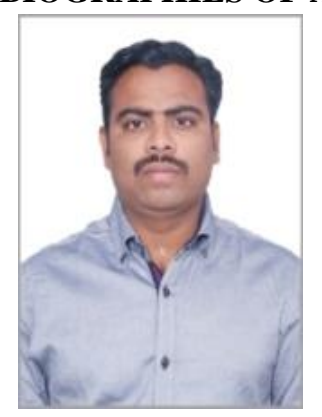

S.Dhandayuthapani received B.E(Electrical and Electronics Engineering) degree, M.E(Power Electronics and Drives) from Annamalai University, Anna university India respectively. He is currently working toward the Ph.D. degree at the SCSVMV University, Kanchipuram, India.

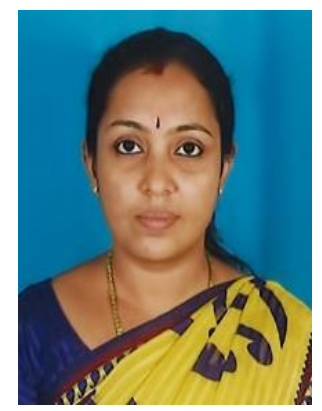

Dr.K.Anisha received B.E (Electrical and Electronics Engineering) degree, M.E (Power Systems) and the Doctoral degree from University of Madras, AVIT, and SCSVMV University India respectively. She is currently working as a Assistant Professor in the Department of Electrical and Electronics SCSVMV University, kanchipuram, India. Her fields of interest include Power Systems, Power quality, active filters, FACTS devices. 